University of Nebraska - Lincoln

DigitalCommons@University of Nebraska - Lincoln

Educational Psychology Papers and

Publications

Educational Psychology, Department of

2006

\title{
Temperament and Language Skills as Predictors of Teacher-Child Relationship Quality in Preschool
}

\author{
Kathleen Moritz Rudasill \\ University of Nebraska-Lincoln, kmrudasill@vcu.edu \\ Sara E. Rimm-Kaufman \\ University of Virginia, ser4x@virginia.edu \\ Laura M. Justice \\ University of Virginia, justice.57@osu.edu \\ Khara Pence \\ University of Virginia
}

Follow this and additional works at: https://digitalcommons.unl.edu/edpsychpapers

Part of the Educational Psychology Commons

Rudasill, Kathleen Moritz; Rimm-Kaufman, Sara E.; Justice, Laura M.; and Pence, Khara, "Temperament and Language Skills as Predictors of Teacher-Child Relationship Quality in Preschool" (2006). Educational Psychology Papers and Publications. 130.

https://digitalcommons.unl.edu/edpsychpapers/130

This Article is brought to you for free and open access by the Educational Psychology, Department of at DigitalCommons@University of Nebraska - Lincoln. It has been accepted for inclusion in Educational Psychology Papers and Publications by an authorized administrator of DigitalCommons@University of Nebraska - Lincoln. 


\title{
Temperament and Language Skills as Predictors of Teacher-Child Relationship Quality in Preschool
}

\author{
Kathleen Moritz Rudasill, Sara E. Rimm-Kaufman, \\ Laura M. Justice, and Khara Pence
}

\author{
Curry School of Education, University of Virginia \\ Corresponding author - Kathleen Moritz Rudasill
}

\begin{abstract}
Current educational policy emphasizes "school readiness" of young children with a premium placed on preschool interventions that facilitate academic and social readiness for children who have had limited learning experiences prior to kindergarten (Rouse, Brooks-Gunn, \& McLanahan, 2005). The teacher-child relationship is viewed as a critical mechanism for the effectiveness of interventions (Girolametto, Weitzman, \& Greenberg, 2003; National Institute of Child Health and Human Development Early Child Care Research Network, 2003). The purpose of this study was to determine how children's temperament and language skills predict teacherchild relationship quality. The sample consisted of 99 at-risk preschool students. Three findings emerged: (a) bolder children with lower language complexity were more likely to have higher levels of conflict in their relationships with teachers, (b) shyer children with greater language complexity were more likely to have dependent relationships with their teachers, and (c) teacher effects accounted for more of the variance in conflictual and dependent teacher-child relationships compared to children's behavioral inhibition and language complexity. This study shows that teacher-child relationships are multirelational. Individual differences in temperament and language skills affect teacher-child interactions, and ultimately, contribute to the effectiveness of classroom interventions. Such information helps to unpack the complexities of classroom quality by increasing awareness among practitioners of factors contributing to positive teacher-child relationships.
\end{abstract}

The current context of educational policy emphasizes "school readiness" of young children. As such, a great premium is placed on designing preschool 
interventions that facilitate academic and social readiness for school, particularly for children who enter elementary school having had limited learning experiences (Rouse, Brooks-Gunn, \& McLanahan, 2005). Most preschool intervention approaches emphasize language enhancement as an essential component to academic success. Considering the substantial individual differences among children in this developmental domain, language interventions have become prevalent mechanisms for "leveling the playing field" for children most at risk for school failure.

Within "language-rich" or "language-focused" interventions, the teacher-child relationship is viewed by many experts as a critical conduit or mechanism for the effects of intervention (e.g., Girolametto, Weitzman, \& Greenberg, 2003; National Institute of Child Health and Human Development Early Child Care Research Network, 2003). Thus, it is critical to consider teacher-child relationship quality as a factor influencing the success of language interventions. To date, few studies have examined such mechanisms, specifically the quality of teacher-child relationships, through which these interventions influence change.

Several factors combine to predict the quality of teacher-child relationships. As such, teacher-child relationships are bidirectional, with teacher and child characteristics functioning in concert to influence the quality of this relationship. Both teachers and children, then, bring certain attributes to their relationships. The purpose of this study was to examine the influence of specific child attributes on teacher-child relationships. We sought to understand the unique contributions of the child characteristics of temperament (shyness) and language skills (operationalized as language complexity) to the quality of the teacher-child relationship. We address two questions.

1. To what extent do children's temperament (shyness) and language skills (language complexity) predict the quality of the teacher-child relationship?

2. When controlling for individual differences among teachers, to what extent do children's temperament (shyness) and language skills (language complexity) predict the quality of the teacher-child relationship?

In the following sections, we summarize research in the areas of teacherchild relationships, temperament, and language skills, particularly in relation to the prekindergarten years.

\section{TEACHER-CHILD RELATIONSHIPS}

Positive teacher-child relationships are an important social resource for young children, with clear, positive contributions for child development and acquisition of social and academic skills. Children who have positive rela- 
tionships with their teachers are more likely to exhibit competent behavior in the classroom and show signs of readiness to learn (Hamre \& Pianta, 2001; Pianta, 1999). This view of the importance of relationships is consistent with Vygotsky's (1962) premise that learning is a social endeavor and occurs most effectively when interactions occur around a child's zone of proximal development. In other words, when adults are sensitive, responsive, aware of a child's growing cognitive abilities, and provide scaffolding to appropriately guide development, children learn best. Therefore, it follows that children who have good relationships with their teachers will experience more productive academic and social development than those children engaged in negative teacher-child relationships, an idea that has been supported both theoretically (Pianta, 1999) and empirically (Hamre \& Pianta, 2001).

Teachers perceive their relationships with children to be positive when there are low levels of conflict and dependency, and high levels of closeness. Specifically, positive relationships are those in which there is a mutual sense of respect and caring between teachers and children, and where children perceive their teachers as trustworthy and secure bases (Pianta, 1999). Research shows that preschool and early elementary age children who have positive relationships with their teachers perform better on achievement tests (Pianta, Nimetz, \& Bennett, 1997), on visual and language measures (Lerner, Lerner, \& Zabski, 1985), and have better work habits and grades than children with negative relationships (Hamre \& Pianta, 2001). Negative relationships, on the other hand, are those where teachers perceive relationships with children to be overly dependent and conflictual. These are relationships where children and teachers experience regular discord or where children are clingy and demanding, showing excessive reliability on the teacher. Children who have negative relationships with their teachers have poor work habits, low frustration tolerance, low school competence, lower achievement test performance, and avoid school and report loneliness more than those who are in positive relationships (Birch \& Ladd, 1997; Pianta et al., 1997). Furthermore, teacher- child relationships in kindergarten predict outcomes through middle school (Hamre \& Pianta, 2001), indicating the long-term value of early teacher-child relationships.

Teacher-child relationships are best considered in terms of bidirectionality, in that relationship quality reflects both teachers' and children's characteristics. This bidirectional influence can be viewed in terms of a "goodness-of-fit" paradigm, implying that both teachers and children contribute to the degree to which children are at ease in the classroom. Pianta's (1999) model of the teacher-child relationship process represents the teacher and child as two separate entities, each with individual developmental history, biological factors, and experiences in relationships. Information exchange processes link the teacher and child and refer to the interactive behaviors between the two. All of these features are integrated within a relationship system between teacher and child (Rimm-Kaufman, 2003). When examining the teacher-child relationship, then, there are two aspects to under- 
stand: what the child brings to the relationship (child attributes such as behavioral inhibition and language complexity) and what the teacher brings (beliefs, perceptions).

\section{Attributes Contributing to Teacher-Child Relationships}

Teacher-child relationship quality is determined by both teacher characteristics and expectations and child characteristics. There is ample evidence suggesting that teachers' perceptions of students influence the quality of the teacher-child relationship (Buss, Gingles, \& Price, 1993; Evans, 1992, 1996; Saft \& Pianta, 2001; Stuhlman \& Pianta, 2002). Saft and Pianta found that teachers' perceptions of their relationships with students are related to both child and teacher attributes. Combinations of attributes, such as child and teacher ethnicity, had the most predictive power over aspects of teacher-child relationship quality. When teacher and child ethnicity matched, teachers had more positive feelings toward students. Zeller (2004) found that teachers' childhood attachment histories and depression levels were both related to teachers' perceptions of teacher-child relationship quality when child attributes were also considered. Specifically, Zeller found that teachers expressing more feelings of depression were also more likely to feel close to their students, indicating that perceptions of relationship quality are colored in part by teachers' emotional states. Taken together, this research suggests that teacher qualities and characteristics contribute to the quality of the teacher-child relationship.

Child characteristics also contribute to teacher-child relationship quality. Certain child characteristics seem to facilitate successful adjustment to school, and teachers may unwittingly award greater academic confidence to those students who respond well to the demands of school (Buss et al., 1993; Keogh, 2003; Lerner et al., 1985). These child characteristics, as they are perceived by teachers, influence the nature of teacher-child interactions, and hence, the quality of the teacher-child relationship (Saft \& Pianta, 2001; Stuhlman \& Pianta, 2002). Indeed, teachers have ideas about the characteristics of "teachable children," so children who do not meet these criteria may be at risk socially and academically in the classroom (Keogh). Children with weaknesses, or perceived weaknesses, in communication may be particularly at-risk because they are unwilling or unable to interact with their teachers. This is exacerbated by teachers' attempts to elicit speech from reticent children who are less likely to speak as the center of attention (Evans, 1992). Because teachers provide the vehicle with which classroom interventions are delivered to children, consideration of the quality of the teacher-child relationship is critical. Specifically, this study is designed to examine how two child characteristics, behavioral inhibition and language complexity, moderate the quality of relationships between teachers and children. 


\section{CONTRIBUTION OF TEMPERAMENT}

Temperament is a broad, multidimensional construct that can be defined as an individual's style of response to stimuli in the environment (Rothbart \& Bates, 1998). Attributes such as intensity and activity levels, persistence, affect, and behavioral inhibition are temperamentally based child characteristics that may contribute to teacher-child relationship quality. Certain attributes ease children's adjustment into student roles, and therefore, are likely to affect teachers' perceptions of their relationships with these children (Entwisle \& Alexander, 1998). The purpose of this article is to focus on behaviorally inhibited and uninhibited styles. These characteristics are highly salient and fairly stable over time. Inhibited and uninhibited styles are likely to be important for understanding the degree to which a child approaches or withdraws from novel experiences and people, and, as such, are as or more likely than other temperament attributes to be important in predicting teacher-child relationship quality in early childhood.

People who are apprehensive toward new people, events, and things are categorically different from others who approach novelty with ease (Caspi \& Silva, 1995; Kagan, Snidman, \& Arcus, 1992). They have a biologically based predisposition to be inhibited. In the general population, approximately $15 \%$ to $20 \%$ of people are inhibited, about $30 \%$ to $35 \%$ of people are uninhibited, and the remainder of the population falls somewhere in between (Kagan, 1997; Kagan et al., 1992; Kagan, Snidman, \& Arcus, 1998). These classifications remain fairly stable for $60 \%$ of children through at least age 9 (Kagan et al., 1998). Children who are inhibited are highly reactive; that is, they show fear in new situations (Kagan, 1994). Kagan and colleagues (1992) reported that children who are uninhibited are low reactive and approach- oriented in new situations, and display fewer fears at 9 and 14 months than their high reactive counterparts. Therefore, high reactivity and fear together predict social inhibition in school. When studied at age 4 , most children who had been low reactive infants talked, smiled, and engaged in spontaneous speech, whereas high reactive children were more likely to stay alone quietly observing (Kagan et al., 1998).

Children's school experiences vary in part because of their temperamentally based individual differences. The transition to kindergarten is often a tumultuous adjustment for children, putting some at risk socially and academically, and temperament may be one determinant of children's ease of adjustment. Research shows that bold or uninhibited children are more socially competent and therefore have more interactions with teachers than their less-bold counterparts (Lerner et al., 1985; Patrick, Yoon, \& Murphy, 1995; Rimm-Kaufman et al., 2002; Rimm-Kaufman \& Kagan, 2005; Skarpness \& Carson, 1986). In addition, they seem to adjust more readily to kindergarten and are viewed by their teachers as more verbal and academically competent compared to their shy counterparts (Lerner et al.). On the other hand, inhibited children appear to fit well into student roles because they are 
likely to be more compliant and refrain from speaking out of turn (Keogh, 2003). However, because of their quiet style, they may elicit less attention from their teachers than uninhibited children; additionally, they may receive less conversation and verbal feedback from their teachers, both of which contribute to children's early learning in the preschool classroom.

For purposes of this study, it is useful to consider how children's shy or bold styles may have implications for the frequency and nature of their interactions with teachers. For example, uninhibited children appear to be more affected than other children by the sensitivity of their teachers, with teacher sensitivity predicting more self-reliance, more positive affect, and fewer negative and off-task behaviors among socially bold children, but not for their wary counterparts (Rimm-Kaufman et al., 2002). These findings suggest that bold children receive more exposure to the teacher than inhibited children. As we seek to understand how teachers operate as a delivery mechanism of interventions, it is important to understand differences in teacher-child relationships between teachers and shy and bold children.

\section{THE ROLE OF LANGUAGE}

Language and communication ability contribute to both academic and social success in preschool and beyond. Learning to read in early elementary school is predicated on early language experiences through which children become exposed to and familiar with letters, phonemes, words, and books, as well as active and varied use of oral communication (Snow, Burns, \& Griffin, 1998). In his review, Pressley (1998) concluded that children who have high quality oral language interactions at home, such as talking and reading with parents, have more complete understandings of their experiences. They have advantages in general cognitive development and communication skills, and later, at comprehending text. Similarly, Girolametto, Weitzman, and Greenberg (2003) found that children with teachers who have been trained in methods to stimulate language exhibit greater language productivity and complexity. Indeed, preschool children's early language and literacy skills serve as robust indicators of children's reading success in early elementary school (Juel, 1988).

Because language complexity subsumes both vocabulary and sentence structure, it is often used as a measure of language skills. More to the point, language complexity has been linked to classroom behavior. As language complexity decreases, problem behavior increases; as language complexity increases, engagement in classroom activities increases (Qi \& Kaiser, 2004). This suggests that language complexity may be a mechanism through which children have higher quality interactions with peers and teachers, resulting in greater benefit from classroom discourse. Through interactions with peers and teachers, children have richer, more meaningful classroom experiences. Stanovich (1986) calls this the "Matthew," or "rich-get-richer" 
(p. 382) effect, where early advantages, or lack thereof, influence cognitive and language development for years.

The purpose of this study is to examine the effects of temperament (behavioral inhibition or shyness) and language skills (language complexity) on the teacher-child relationship, which leads to two questions. First, in what ways do shyness and language complexity predict the quality of the teacher-child relationship? Second, because teacher-child relationships are multiply determined, in what way does controlling for teacher effects change the influence of behavioral inhibition and language complexity on the quality of the teacher-child relationship? Given the importance of communication to classroom discourse and relationship building, we hypothesize that both temperament and language will contribute to teacher-child relationship quality.

\section{METHOD}

This study was conducted as part of the Preschool Curriculum Evaluation Research Project (PCER) at the University of Virginia. PCER is a multisite consortium funded by the U.S. Department of Education Institute of Education Sciences to characterize the effectiveness of various preschool interventions. The Virginia site, led by Justice and colleagues, is documenting, through a randomized clinical trial, the effectiveness of the Language Focused Curriculum (LFC; Bunce, 1995; Rice \& Wilcox, 1995) on language and social development from prekindergarten through first grade. The LFC is a classroom-based thematic curriculum that emphasizes teachers' high-quality conversational interactions with children as a route to accelerating children's language growth. The cohort used for this study is made up of approximately 196 preschool children from low-income households who are attending preschool programs designed for children "at risk" for school failure based on sociodemographic indicators.

\section{Participants}

Children. Children for this study were randomly selected from the first cohort of children at the Virginia site. Each child was assigned a random number; the children with the 10 lowest numbers were selected from each sample classroom for assessment of teacher-child relationship quality using the Student-Teacher Relationship Scale (STRS; Pianta, 2001). The STRS was completed by teachers in the spring of 2004. Prior to data analysis, we decided to include only those children for whom all measures for this study were complete and for whom English is the primary language. For the subset of children in this study, 12 were eliminated due to incomplete data and 1 was eliminated due to language. The final sample consisted of 99 children ranging in age from 4.7 to 5.6 years at the time of the 
spring 2004 data collection. No demographic data were available for 2 of the 99 children; Table 1 displays the gender and ethnicity of the remaining 97 children. A chi-square test for goodness of fit shows that the ethnic distribution of participants in this subsample is similar to the full sample, $x^{2}(3)=3.14, p>.05$.

Teachers. All teachers in the sample were White women, ranging in age from 25 to 54 years and in classroom experience from 3 to 27 years. Table 2 shows demographic information for the teachers in the sample. Of the 13 public preschool classrooms in this study, six of the classrooms were affiliated with Head Start and seven were funded through Title 1 or the state's public prekindergarten initiative.

Table 1. Child Characteristics

\begin{tabular}{|c|c|c|c|c|}
\hline \multirow[b]{2}{*}{ Characteristic } & \multicolumn{2}{|c|}{ Girls $n=47$} & \multicolumn{2}{|c|}{ Boys $n=50$} \\
\hline & Mean & SD & Mean & SD \\
\hline \multicolumn{5}{|l|}{ Age in years } \\
\hline (At spring assessment) & 5.2 & .28 & 5.2 & .33 \\
\hline \multicolumn{5}{|l|}{ Ethnicity } \\
\hline White & 33 & & 38 & \\
\hline Black or African American & 12 & & 9 & \\
\hline Hispanic or Latino & 1 & & 0 & \\
\hline Other ethnic groups & 1 & & 2 & \\
\hline Unspecified ethnicity & 0 & & 1 & \\
\hline
\end{tabular}

Table 2. Teacher Characteristics

\begin{tabular}{lccccc}
\hline & \multicolumn{2}{c}{ Head Start Program $n=6$} & & \multicolumn{2}{c}{ Title I Program $n=7$} \\
\cline { 2 - 3 } Characteristic & Mean & SD & & Mean & SD \\
\hline Teacher & 44.9 & 7.3 & & 43 & 8.8 \\
Age & 9.2 & 4.5 & 14.4 & 10.2 \\
Years experience & $\$ 26,078$ & $\$ 6329$ & & $\$ 33,757$ & $\$ 7674$ \\
Annual salary & & & & 0 \\
Teacher education & & & & 6 \\
$\quad \begin{array}{l}\text { Associate's degree or some college } \\
\text { Bachelor's degree }\end{array}$ & 3 & & 1 \\
Master's degree & 0 & & \\
\hline
\end{tabular}




\section{Measures}

The following measures were used for this study: (a) the StudentTeacher Relationship Scale (STRS; Pianta, 2001), (b) the shyness scale of the Children's Behavior Questionnaire (CBQ; Rothbart, 1996), and (c) transcriptions of language samples from 10-min dyadic play sessions between each child and a researcher.

Student-Teacher Relationship Scale. Teacher-child relationship quality was measured by teachers in the spring of 2004 using the STRS (Pianta, 2001), a 28-item teacher-report questionnaire designed to capture the teachers' perceptions of their relationships with each child. This scale measures three constructs of the teacher-child relationship (conflict, dependency, and closeness) with a rating scale from 1 to 5. Spring STRS scores were used for this study based on our expectation that spring assessments of teacher-child relationships would better reflect the true quality of those relationships, because teachers had enough time to get to know their students. Cronbach's alpha for each subscale, using this sample, are as follows: .92 (conflict), .84 (closeness), and .70 (dependency), suggesting high scale reliability. These values are very similar to those reported by Pianta (2001) with a normative sample of 1,535 (conflict, .92; closeness, .86; dependency, .64).

The conflict scale comprises 12 items. A high conflict score means "that the teacher struggles with the student, perceives the student as angry or unpredictable, and consequently the teacher feels emotionally drained and believes he/she is ineffective" (Pianta, 2001, p. 2). The closeness scale is made up of 11 items; a high closeness score indicates "that the relationship is characterized by warmth, and the teacher believes he or she is effective because the student uses the teacher as a source of support" (Pianta, 2001, p. 2). Finally, the dependency scale has 5 items, and a high dependency score means that the "teacher perceives a particular student as overly dependent on him/her ... the student reacts strongly to separation from the teacher, requests help when not needed, and consequently the teacher is concerned about the student's overreliance" (Pianta, 2001, p. 2).

Children's Behavior Questionnaire. Behavioral inhibition or shyness was measured with the 13-item shyness subscale of the CBQ (Rothbart, 1996). The CBQ is designed for completion by a caregiver about a child. Teachers and teachers' aides completed this subscale of the CBQ for each child in May 2004. Because the STRS is a teacher-report measure of the quality of the teacher-child relationship, only teachers' aides' CBQ ratings were used. The teachers' and teachers' aides' CBQ scores were highly correlated $(r=.78)$. The internal reliability measured with Cronbach's alpha for this scale, as reported by Rothbart (1996), is very high (.94). Cronbach's alpha for this sample is also high (.95) with scores normally distributed $(M=44.1, S D=19.41)$. This scale includes items like "sometimes prefers to 
watch rather than join other children playing" and "is sometimes shy even around people s/he has known a long time."

Language samples. Language complexity was measured using language samples from videotapes or audiotapes of 10-min dyadic play sessions between each child and a researcher unfamiliar to the child. The play sessions were timed to ensure that they were exactly 10 min in duration. Researchers used Play-Doh@ and other props (e.g., a farm set with animals, a picnic basket with plastic food) as springboards for discussion and asked as many open-ended questions as possible to encourage child language. Language samples were collected in the fall of the 2003 to 2004 school year. Each language sample was transcribed using the Systematic Analysis of Language Transcripts, Research Version 8.0 (SALT) software program which calculates a variety of language productivity and complexity measures. All transcribers were trained for approximately $6 \mathrm{hr}$ by transcribing and applying SALT codes to five practice transcripts, then assessing interrater reliability. Transcribers were deemed reliable if they averaged $90 \%$ or greater agreement with a faculty researcher on consistency in utterance segmentation, transcript accuracy, and SALT convention accuracy. To bolster reliability further, each transcript was coded by one person, then checked by a second transcriber for accuracy. Both transcribers listened to words or utterances up to three times before indicating unintelligibility.

Commonly used language complexity scores (mean length of utterance in words and mean length of utterance in morphemes) were calculated using SALT and were correlated with the teachers' aides' CBQ scores. Owing to the fact that spontaneity of speech is a commonly used indicator of bold behavior (Kagan, 1994), language complexity measures, rather than productivity measures, were selected so that they would not confound with shyness. Mean length of utterance in words (MLU in words) and mean length of utterance in morphemes (MLU in morphemes) measure sentence complexity. Specifically, these values represent the number of words or morphemes a child averages per utterance.

\section{Data Analysis}

To determine the contribution of language complexity and shyness on the quality of the teacher-child relationship, two sets of three regression analyses were conducted. In the first set, each of the three STRS subscales served as dependent variables, with language complexity (determined by mean MLU, an aggregated score of mean length of utterance in morphemes and mean length of utterance in words), shyness (CBQ scores determined by classroom aides), and an interaction term for language and shyness entered as independent variables.

A second set of regression analyses was run to determine the effects of temperament and language skills above and beyond individual teacher 
effects. Because teacher-child relationship quality is assessed through teacher report, we first examined each teacher's mean scores on the STRS subscales. As a consideration of individual differences among teachers' scores, the second set of regression analyses included two blocks of variables to account for teacher effects. In the first block, teachers were entered as dummy variables. In the second block, language complexity (mean $\mathrm{MLU})$, shyness (CBQ scores determined by classroom aides), and an interaction term for language and shyness were entered.

\section{RESULTS}

\section{Description}

Correlation coefficients were computed and showed low correlations between the shyness measure (CBQ subscale) and the language complexity measure (mean length of utterance of words and morphemes); for CBQ and MLU in words, $r=.13$, and for CBQ and MLU in morphemes, $r=.13$. Because MLU in words and MLU in morphemes were highly correlated $(r=.99, p<.001)$, the measures were combined into one language complexity measure.

The variability among the teachers' mean conflict $(M=40.09, S D=$ 17.52 , range $=13.37$ to 67$)$, closeness $(M=57.49, S D=16.71$, range $=28.33$ to 84.38$)$, and dependency $(M=47.89, S D=17.56$, range $=16$ to 83.25$)$ scores for children suggested the importance of considering individual differences in teachers in predicting quality of the teacher-child relationship. Table 3 shows mean conflict, closeness, and dependency scores for each teacher. Correlations among these values suggest that teachers who report high conflict also report high dependency and low closeness levels in their relationships with children. Table 4 displays descriptive statistics for the three STRS subscales, conflict, closeness, and dependency, across all students as perceived by teachers. The mean values for each of these subscales suggest that the typical teacher perceives more closeness than conflict or dependency in her relationships with students.

\section{Question 1: How Do Language Complexity and Shyness Predict the Quality of the Teacher-Child Relationship?}

Table 5 shows results of the first set of regression analyses. In predicting conflict, $F(3,95)=3.828, p=.012, R^{2}=.11$, and dependency, $F(3,95)=$ $6.892, p=.000, R^{2}=.18$, the models were significant. In predicting closeness, the model was nonsignificant. For conflict, children who were less shy with lower language complexity showed more conflict with their teachers. For dependency, the interaction of shyness and language complexity approached significance $(p=.09)$; shyer children with high language complexity showed more dependency on their teachers. 
Table 3. Mean Teacher Scores on the Student-Teacher Relationship Scale Subscales Across All 10 Children in the Classroom

\begin{tabular}{lccc}
\hline Teacher & Mean Conflict & Mean Closeness & Mean Dependency \\
\hline T1 & 41.5 & 69.5 & 55 \\
T2 & 21.5 & 82 & 37.7 \\
T3 & 16.7 & 64.3 & 21.4 \\
T4 & 49 & 28.3 & 50.8 \\
T5 & 67 & 29.6 & 58.9 \\
T6 & 29.6 & 52.1 & 16 \\
T7 & 32.8 & 56.3 & 49 \\
T8 & 66.2 & 56.6 & 48.6 \\
T9 & 57.6 & 45.6 & 30 \\
T10 & 47.3 & 51 & 55.7 \\
T11 & 13.4 & 84.4 & 50.9 \\
T12 & 51 & 53.4 & 61.8 \\
T13 & 51 & 56.4 & 83.3 \\
\hline
\end{tabular}

Table 4. Mean Total Scores for Student-Teacher Relationship Scale Subscales

\begin{tabular}{llll}
\hline Subscale & N & Mean & SD \\
\hline Conflict & 99 & 42.31 & 31.21 \\
Closeness & 99 & 57.54 & 27.17 \\
Dependency & 99 & 47.98 & 30.20 \\
\hline
\end{tabular}

To interpret the interactions for conflict and dependency, the sample was divided into three temperament groups in accordance with Kagan, Snidman, and Arcus's (1998) findings for the distribution of inhibition in the general population - 20\% inhibited (shy), 35\% uninhibited (bold), and $45 \%$ neither inhibited nor uninhibited (middle). ${ }^{1}$ For each temperament group, conflict and dependency were regressed on language complexity. Table 6 shows results of the second series of regression analyses. The regression model for conflict among the bold group, $F(1,33)=3.86, p$ $=.058, R^{2}=.11$, approached significance. These analyses indicated that, for the bold group, lower language complexity predicts conflict in the teacherchild relationship. The regression models for dependency among the shy, $F(1,18)=4.46, p=.049, R^{2}=.20$, and middle groups, $F(1,42)=10.02$,

1. Owing to the fact that this population may not follow the same pattern of inhibition, the sample was also divided into three equal parts according to shyness scores (more inhibited, moderate, and less inhibited). All regression analyses using shyness groups according to Kagan, Snidman, Arcus (1998) were conducted using three equal groups, yielding the same results. 
Table 5. Predicting Student-Teacher Relationship Scale Scores From Language and Temperament

\begin{tabular}{|c|c|c|c|c|c|c|}
\hline & \multicolumn{2}{|c|}{$\begin{array}{l}\text { Conflict } \\
R^{2}=.108^{*}\end{array}$} & \multicolumn{2}{|c|}{$\begin{array}{l}\text { Closeness } \\
R^{2}=.003\end{array}$} & \multicolumn{2}{|c|}{$\begin{array}{l}\text { Dependency } \\
R^{2}=.179^{* * *}\end{array}$} \\
\hline & $\beta$ & $t$ & $\beta$ & $t$ & $\beta$ & $t$ \\
\hline Language complexity & -.390 & -1.762 & -.110 & -.471 & .021 & .098 \\
\hline Shyness & -1.842 & $-2.821^{* *}$ & -.372 & -.539 & -.945 & -1.507 \\
\hline Language Complexity $\times$ Shyness & 1.797 & $2.544^{*}$ & .382 & .511 & 1.177 & 1.736 \\
\hline
\end{tabular}

${ }^{*} p<.05 ;{ }^{* *} p<.01 ;{ }^{* *} p<.001$

Table 6. Predicting Conflict and Dependency by Temperament Group From Language Complexity

\begin{tabular}{|c|c|c|c|c|c|c|c|c|}
\hline & \multicolumn{4}{|c|}{ Conflict } & \multicolumn{3}{|c|}{ Dependency } & \multirow[b]{2}{*}{$t$} \\
\hline & $n$ & $R^{2}$ & $\beta$ & $t$ & $n$ & $R^{2}$ & $\beta$ & \\
\hline Most shy & 20 & .129 & .359 & 1.631 & 20 & $.198^{*}$ & $.445^{\star}$ & 2.111 \\
\hline Middle & 44 & .075 & .273 & 1.840 & 44 & $.193^{\star *}$ & $.439^{* *}$ & 3.165 \\
\hline Least shy & 35 & .105 & -.324 & -1.964 & 35 & .029 & .172 & 1.001 \\
\hline
\end{tabular}

${ }^{*} p<.05 ;{ }^{* *} p<.01$

$p=.003, R^{2}=.19$, were both significant. Analysis of the regression slopes shows that, for all but the boldest children, greater language complexity predicts dependency in the teacher-child relationship.

To further understand the interaction between behavioral inhibition and language complexity as they predict conflict and dependency, regression lines were calculated for each temperament group (shy, middle, bold). The resulting slopes for each temperament group show the level of teacher-child conflict (Figure 1) and dependency (Figure 2) predicted by language complexity for the average shy, middle, and bold child.

Question 2: After Controlling for Teacher Effects, How Do Language Complexity and Shyness Predict the Quality of the Teacher-Child Relationship?

Regression analyses were conducted to account for teacher effects to determine the influence of shyness and language complexity on the teacherchild relationship above and beyond the effects of teachers. Each of the 


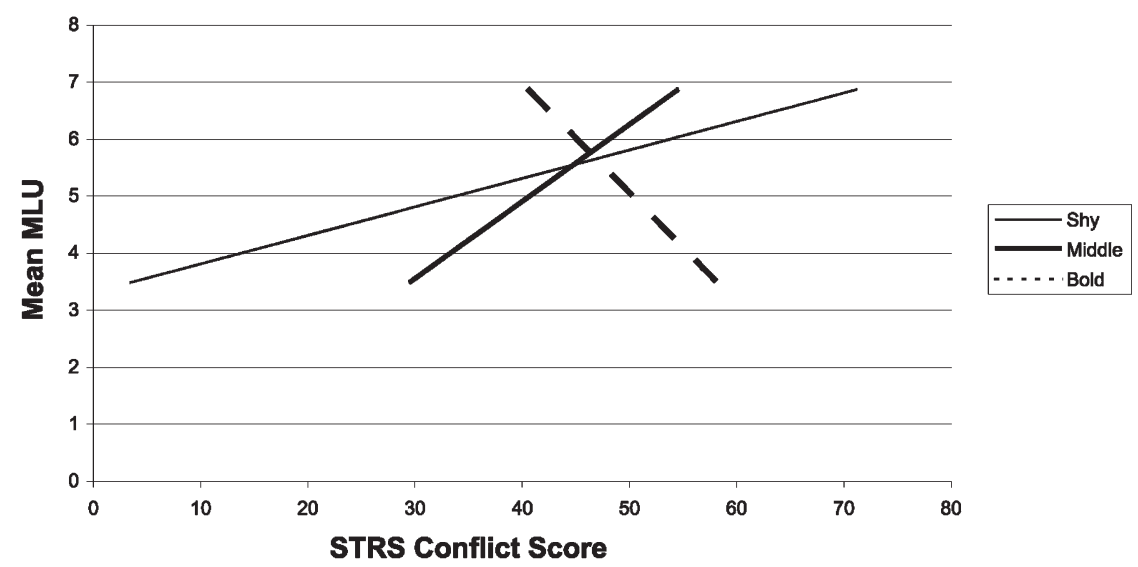

Figure 1. Conflict by language complexity (mean MLU) moderated by shyness level (shy, middle, bold).

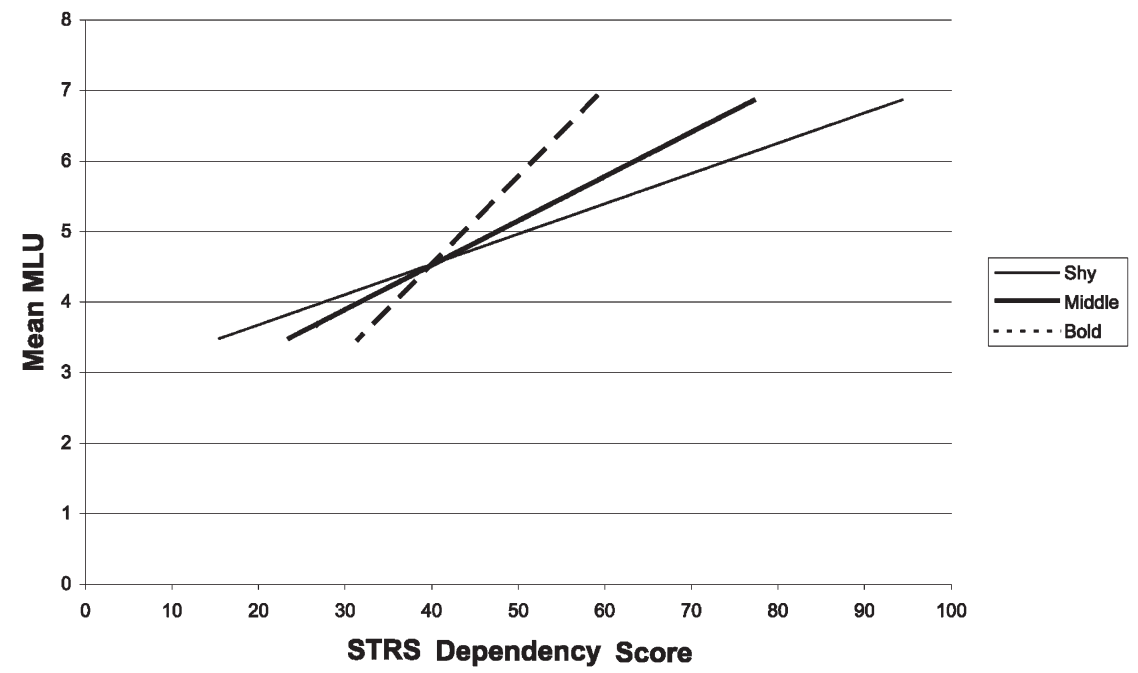

Figure 2. Dependency by language complexity (mean MLU) moderated by shyness level (shy, middle, bold).

three regression analyses was a two-step regression with dummy-codes for teachers used in the first block, and language, shyness, and interaction terms used in the second block. The first block (teachers) accounted for $43 \%$ of the variance, $F(12,84)=5.28, p<.001$, in conflict; $61 \%, F(12,84)=4.14$, $p<.001$, in closeness; and 34\%, $F(12,84)=3.59, p<.001$, in dependency. Table 7 provides the results of the second block of these regression analyses. In predicting conflict and closeness, the models were not statistically 
Table 7. Predicting Student-Teacher Relationship Scale Scores From Language and Temperament While Controlling for Teacher Effects

\begin{tabular}{|c|c|c|c|c|c|c|}
\hline & \multicolumn{2}{|c|}{$\begin{array}{l}\text { Conflict } \\
R^{2}=.038\end{array}$} & \multicolumn{2}{|c|}{$\begin{array}{c}\text { Closeness } \\
R^{2}=.030\end{array}$} & \multicolumn{2}{|c|}{$\begin{array}{c}\text { Dependency } \\
R^{2}=.126^{\star *}\end{array}$} \\
\hline & $\beta$ & $t$ & $\beta$ & $t$ & $\beta$ & $t$ \\
\hline Language complexity & -.395 & -1.971 & -.357 & -1.680 & -.099 & -.490 \\
\hline Shyness & -1.105 & -1.906 & -.950 & -1.545 & -.980 & -1.685 \\
\hline Language Complexity $\times$ Shyness & 1.088 & 1.742 & .935 & 1.413 & 1.308 & $2.089^{*}$ \\
\hline
\end{tabular}

Table 8. Predicting Dependency by Temperament Group From Language While Controlling for Teacher Effects

\begin{tabular}{lcccc}
\hline & \multicolumn{4}{c}{ Dependency } \\
\cline { 2 - 5 } & $n$ & $R^{2}$ change & $\beta$ & $t$ \\
\hline Most shy & 20 & .137 & .555 & $2.410^{*}$ \\
Middle & 44 & .001 & .042 & .224 \\
Least shy & 35 & .005 & .102 & .497 \\
\hline
\end{tabular}

${ }^{*} p<.05$

or practically significant. In predicting dependency, the $\mathrm{R}^{2}$ change was significant, $F(3,81)=6.34, p=.001 ; R^{2}=.126$, and results showed an interaction between shyness and language, $t=2.089, p=.04$. To further understand the interactions for dependency, the sample was divided into three temperament groups as described earlier. For each temperament group, dependency was regressed on language complexity, as measured by mean MLU to examine the interaction effect between shyness and language on dependency.

The results of the regression analyses for dependency are shown in Table 8 . These analyses reveal that, for the inhibited or most shy group, greater language complexity predicted greater dependency in the teacherchild relationship $(\beta=.555, t=2.410, p=.047)$, but that there were no comparable effects for the middle or least shy groups.

The influence of teacher effects on teacher-child relationship quality is further illustrated through examination of the variance explained by child characteristics of behavioral inhibition and language complexity. Before controlling for individual differences among teachers, behavioral inhibition and language complexity accounted for $11 \%$ of conflict, a moderate effect size. However, after controlling for teacher effects, the unique contri- 
bution of behavioral inhibition and language complexity was reduced to $4 \%$, a small effect size. For dependency, before controlling for teacher effects, behavioral inhibition and language complexity accounted for $18 \%$ of variance, a moderate to large effect size. After controlling for teacher effects, the unique contribution of behavioral inhibition and language complexity was reduced slightly to $13 \%$, a moderate effect size. For closeness, before controlling for teacher effects, behavioral inhibition and language complexity accounted for only .3\% of closeness, a negligible amount of variance. Interestingly, while controlling for teacher effects, behavioral inhibition and language complexity had a small effect size of $3 \%$.

\section{DISCUSSION}

Three conclusions emerged from these analyses. First, bolder children with lower language complexity were more likely to have higher levels of conflict in their relationships with teachers than their shyer and more "language-able" peers. Although this relationship was statistically significant only before controlling for teacher effects, the trend in this direction persisted after controlling for teacher effects. The nature of bold or uninhibited children is to be approach-oriented and show little fear toward the unfamiliar (Kagan, 1994). Typically these children are described as assertive and attention seeking in the classroom (Keogh, 2003). These bold characteristics combine to produce children who are more likely to show externalizing problems, making them more at risk than their less-bold peers for behavior problems that disrupt classroom activities such as acting out or calling out (Keogh, 2003; Rimm-Kaufman \& Kagan, 2005). The attachment literature offers an alternative view of teachers' perceptions of conflict in their relationships with children. It is plausible that bold children are insecure-avoidant in their attachment relationships and extend avoidant behaviors to their relationships with teachers (Pianta, 1999; Thompson, 1998). As such, teacher-child relationships would likely be conflictual. However, instead of viewing conflictual relationships as negative, it is possible that teachers' perceptions of negativity show evidence of meaningful engagement between teachers and children, as opposed to situations where children are largely ignored by their teachers. Taken together, these findings suggest that teachers perceive a bold child with poor language ability as more difficult in the classroom than a shy child with poor language ability or another bold child with higher language ability.

Second, shyer children with greater language complexity were more likely to have dependent relationships with their teachers. Again, the nature of this relationship changed when controlling for teacher effects, but remained significant for the shyest group of children. Shy or inhibited children are subdued and wary in new situations and withdraw from the 
unfamiliar (Kagan, 1994). Inhibited children generally receive less attention from teachers than their uninhibited peers, and have fewer social relationships (Keogh, 2003). Therefore, although unlikely to display behavior problems, inhibited children are very much at risk for social isolation in the classroom (Keogh, 2003). It follows that a shy child with strong language skills would be more likely to develop a dependent relationship with a teacher, using language ability to seek attention that may not be otherwise forthcoming. Shy children with superior language skills appear to use their abilities to solicit attention from the teacher.

Third, teacher effects are more important than child characteristics (behavioral inhibition and language complexity) as influences on the quality of the teacher-child relationship. Variation in mean scores for teachers' perceptions of conflict, closeness, and dependency suggests a strong teacher effect with regard to teacher-child relationship quality. Table 3 shows these mean scores. Some teachers (about 19\%) had low conflict and dependency scores relative to closeness, indicating that they cultivate positive relationships with children. On the other hand, some teachers (about $23 \%$ ) had high conflict and dependency scores relative to closeness, indicating that certain teacher attributes dictate negative patterns in teacherchild relationships. In addition, some teachers (about 35\%) had relatively equal scores across all three domains. These findings have implications for future work focusing on teacher factors that contribute to teacher-child relationship quality.

\section{Individual Differences Among Teachers}

Individual differences among teachers influenced the negative aspects of teacher-child relationships more than positive aspects. This was especially evident with the aspect of conflict, where children's behavioral inhibition and language complexity no longer significantly predicted conflict once teacher effects were controlled. Indeed, teacher effects accounted for more of the variance in conflictual and dependent teacher-child relationships compared to child characteristics (e.g., behavioral inhibition and language complexity). This is consistent with other research (Saft \& Pianta, 2001) showing that teacher and child characteristics are more predictive of negative rather than positive aspects of the teacher-child relationship. Specifically, behavioral inhibition and language complexity predicted relationship conflict and dependency, but failed to predict closeness, the aspect of mutual caring and respect between teachers and children.

Examination of the variance explained by behavioral inhibition and language complexity shows that teacher effects operate differently in negative and positive relationships, and further illustrates teachers' influence on negative relationship quality. For conflict and dependency, controlling for teacher effects reduced the influence of children's behavioral inhibition and language complexity. On the other hand, for closeness, controlling for 
teacher effects increased the influence of children's behavioral inhibition and language complexity. It appears that teacher-child relationship quality is especially vulnerable to negative affect from teachers. This is supported by Stuhlman and Pianta (2002) who reported that teachers who expressed negative emotions about students also demonstrated more negative behavior toward those students. Taken together, these findings provide further evidence of how the teacher and child factors combine to contribute to the quality of the teacher-child relationship, suggesting the importance of a relational model when examining this bond.

Finally, a unique aspect of this study requires mention. This study examined the contribution of child characteristics to the teacher-child relationship, taking careful steps to avoid observer bias. Whereas classroom teachers evaluated their relationships with children, classroom aides evaluated child temperament, and outside observers assessed language complexity.

\section{Limitations}

There are two limitations requiring mention. First, this study relies on teacher and teacher aide reports, rather than observation. Although observer bias was avoided by assessing behavioral inhibition and language complexity from sources independent of the lead teacher who assessed teacher-child relationship quality, this study would be improved by using laboratory or classroom observational measures to assess temperament, teacher-child relationship quality, and the observed characteristics of teacher-child interactions. Second, the number of teachers in this study was small for making strong assertions about teacher effects. Replication of the study with a larger sample of teachers would add value to these findings.

\section{CONCLUSIONS}

This study adds to the literature on the nature of teacher-child relationships in early childhood, and provides some insight into what child attributes may contribute to the quality of these relationships, particularly for negative aspects. Individual differences in behavioral inhibition and language complexity influence "goodness of fit" between teachers and children by affecting teacher-child interactions that, in turn, contribute to children's adjustment to and comfort in the classroom. Identifying teacher and child predictors of successful relationships is essential for understanding the effectiveness of classroom interventions. Such information can begin to unpack the complexities of classroom quality by increasing awareness among practitioners of those factors that may contribute to positive teacher-child relationships. 
Findings from this study point to two areas of future research. First, these results illustrate that child characteristics are important to classroom processes. Therefore, contributions of specific child attributes, such as temperament, on the effectiveness of classroom interventions, should be further investigated. Second, although this study illustrates the contribution of behavioral inhibition and language complexity to teacher-child relationship quality, it is also clear that there are other factors contributing to this relationship that were beyond the scope of this article. Therefore, further examination of teacher attributes that may influence teacherchild relationship quality is an area in need of research. For example, studies with more teachers should be undertaken to fully understand "goodness of fit" between teachers and children in classrooms. There is evidence that characteristics such as teacher ethnicity and gender (Stuhlman \& Pianta, 2002), emotional well-being (Zeller, 2004), and personality and communication style are important factors to understand relative to teachers' abilities to support children's learning. Indeed, our finding that teacher effects were more important to teacher-child relationships than both child shyness and language complexity suggests that there is a critical need for further understanding teacher contributions to classroom processes.

\section{ACKNOWLEDGMENTS}

The findings reported here are based on research conducted as part of the Preschool Curriculum Evaluation Research (PCER) program funded by the Institute of Education Sciences (IES), U. S. Department of Education through Grant R305J030084 to the University of Virginia. The content of this publication does not necessarily reflect the views or policies of the PCER Consortium members (including IES), and mention of trade names, commercial products, or organizations does not imply endorsement by the United States government.

We would like to thank Alice Wiggins, Tim Konold, Xitao Fan, and Bob Pianta for assistance with this study.

\section{REFERENCES}

Birch, S. H., \& Ladd, G. W. (1997). The teacher-child relationship and children's early school adjustment. Journal of School Psychology, 35, 61-79.

Bunce, B. (1995). Building a language-focused curriculum for the preschool classroom, volume II: A planning guide. Baltimore: Brookes.

Buss, K., Gingles, J., \& Price, J. (1993). Parent-teacher temperament ratings and student success in reading. Reading Psychology: An International Quarterly, 14, 311-323. 
Entwisle, D. R., \& Alexander, K. L. (1998). Facilitating the transition to first grade: The nature of transition and research on factors affecting it. The Elementary School Journal, 98, 351-364.

Evans, M. A. (1992). Control and paradox in teacher conversations with shy children. Canadian Journal of Behavioural Science, 24, 502-516.

Evans, M. A. (1996). Reticent primary grade children and their more talkative peers: Verbal, nonverbal, and self-concept characteristics. Journal of Educational Psychology, 88, 739-749.

Girolametto, L., Weitzman, E., \& Greenberg, J. (2003). Training day care staff to facilitate children's language. American Journal of Speech-Language Pathology, 12, 299-311.

Hamre, B. K., \& Pianta, R. C. (2001). Early teacher-child relationships and the trajectory of children's school outcomes through eighth grade. Child Development, 72, 625-638.

Juel, C. (1988). Learning to read and write: A longitudinal study of 54 children from first through fourth grades. Journal of Educational Psychology, 80, 417-447.

Kagan, J. (1994). Galen's prophecy: Temperament in human nature. New York: Basic Books.

Kagan, J. (1997). Temperament and the reactions to unfamiliarity. Child Development, 68, 139-143.

Kagan, J., Snidman, N., \& Arcus, D. (1992). Initial reactions to unfamiliarity. Current Directions in Psychological Science, 1, 171-174.

Kagan, J., Snidman, N., \& Arcus, D. (1998). Childhood derivatives of high and low reactivity in infancy. Child Development, 69, 1483-1493.

Keogh, B. (2003). Temperament in the classroom: Understanding individual differences. Baltimore: Brookes.

Lerner, J. V, Lerner, R. M., \& Zabski, S. (1985). Temperament and elementary school children's actual and rated academic performance: A test of 'goodnessof-fit' model. Journal of Child Psychology and Psychiatry, 26, 125-136.

National Institute of Child Health and Human Development Early Child Care Research Network. (2003). Does quality of child care affect child outcomes at age $4 \frac{1}{12}$ ? Developmental Psychology, 39, 451-469.

Patrick, H., Yoon, K. S., \& Murphy, A. (1995, March). Personality characteristics, social competence, and early school adjustment: A contextual and developmental perspective. Paper presented at the meeting for the Society for Research in Child Development, Indianapolis, IN.

Pianta, R. C. (1999). Enhancing relationships between children and teachers. Washington, DC: American Psychological Association.

Pianta, R. C. (2001). Student-teacher relationship scale. Odessa, FL: Psychological Assessment Resources.

Pianta, R. C., Nimetz, S. L, \& Bennett, E. (1997). Mother-child relationships, teacher-child relationships, and school outcomes in preschool and kindergarten. Early Childhood Research Quarterly, 12, 263-280.

Pressley, M. (1998). Reading instruction that works: The case for balanced teaching. New York: Guilford. 
Qi, C. H., \& Kaiser, A. P. (2004). Problem behaviors of low-income children with language delays: An observation study. Journal of Speech, Language, and Hearing Research, 47, 595-609.

Rice, M. L., \&Wilcox, K. A. (1995). Building a language-focused curriculum for the preschool classroom, volume I. Baltimore: Brookes.

Rimm-Kaufman, S. E. (2003, January). Predicting competent classroom behavior: The contribution of early behavioral attributes and qualities of teacher-child interactions. Paper presented at the American Association of Colleges for Teacher Education Conference, New Orleans, LA.

Rimm-Kaufman, S. E., Early, D. M., Cox, M. J., Saluja, G., Pianta, R. C., Bradley, R. H., et al. (2002). Early behavioral attributes and teachers' sensitivity as predictors of competent behavior in the kindergarten classroom. Applied Developmental Psychology, 23, 451-470.

Rimm-Kaufman, S. E., \& Kagan, J. (2005). Infant predictors of kindergarten behavior: The contribution of inhibited and uninhibited temperament types. Behavioral Disorders, 30, 329-346.

Rothbart, M. K. (1996) Children's behavior questionnaire. Eugene: University of Oregon.

Rothbart, M. K., \& Bates, J. E. (1998). Temperament. In W. Damon (Series Ed.) \& N. Eisenberg (Vol. Ed.), Handbook of child psychology: Vol. 3. Social, emotional and personality development (5th ed., pp. 105-176). New York: Wiley.

Rouse, C., Brooks-Gunn, J., \& McLanahan, S. (2005). School readiness: Closing racial and ethnic gaps, introducing the issue. The Future of Children, 15, 5-14.

Saft, E., \& Pianta, R. (2001). Teachers' perceptions of their relationships with students: Effects of child age, gender, and ethnicity of teachers and children. School Psychology Quarterly, 16, 125-141.

Skarpness, L. R., \& Carson, D. K. (1986). Temperament, communicative competence and the psychological adjustment of kindergarten children. Psychological Reports, 59, 1299-1306.

Snow, C. E., Burns, M. S., \& Griffin, P. (Eds.). (1998). Preventing reading difficulties in young children. Washington, DC: National Academy Press.

Stanovich, K. E. (1986). Matthew effects in reading: Some consequences of individual differences in the acquisition of literacy. Reading Research Quarterly, 21, 360-407.

Stuhlman, M., \& Pianta, R. (2002). Teachers' narratives about their relationships with children: Associations with behavior in classrooms. The School Psychology Review, 31, 148-163.

Thompson, R. A. (1998). Early sociopersonality development. In N. Eisenberg (Ed.) \&W. Damon (Series Ed.), Handbook of child psychology: Vol. 3. Social, emotional, and personality development (5th ed., pp. 25-104). New York: Wiley.

Vygotsky, L. S. (1962). Thought and language. Cambridge, MA: MIT Press.

Zeller, J. L. (2004). Teachers' childhood attachments and teacher-student relationships. Unpublished doctoral dissertation, University of Virginia, Charlottesville. 